\title{
How much CO was emitted by the 2010 fires around Moscow?
}

\author{
M. Krol ${ }^{1,2,3}$, W. Peters ${ }^{1}$, P. Hooghiemstra ${ }^{2,3}$, M. George ${ }^{4}$, C. Clerbaux ${ }^{4,5}$, D. Hurtmans ${ }^{5}$, D. McInerney ${ }^{6}$, F. Sedano ${ }^{6}$, \\ P. Bergamaschi ${ }^{6}$, M. El Hajj ${ }^{7}$, J. W. Kaiser ${ }^{8,9,10}$, D. Fisher ${ }^{11}$, V. Yershov ${ }^{11}$, and J.-P. Muller ${ }^{11}$ \\ ${ }^{1}$ Meteorology and Air Quality, Wageningen University, Wageningen, the Netherlands \\ ${ }^{2}$ Institute for Marine and Atmospheric Research Utrecht, Utrecht University, Utrecht, the Netherlands \\ ${ }^{3}$ Netherlands Institute for Space Research SRON, Utrecht, the Netherlands \\ ${ }^{4}$ UPMC Univ. Paris 06; Université Versailles St-Quentin; CNRS/INSU, LATMOS-IPSL, Paris, France \\ ${ }^{5}$ Spectroscopie de l'Atmosphère, Chimie Quantique et Photophysique, Université Libre de Bruxelles (ULB), Brussels, \\ Belgium \\ ${ }^{6}$ European Commission, Joint Research Centre, Institute for Environment and Sustainability, I-21027 Ispra (VA), Italy \\ ${ }^{7}$ NOVELTIS, Ramonville Saint Agne, France \\ ${ }^{8}$ ECMWF, Reading, UK \\ ${ }^{9}$ Max-Planck-Institute for Chemistry, Mainz, Germany \\ ${ }^{10}$ King's College London, London, UK \\ ${ }^{11}$ UCL Dept. of Space \& Climate Physics, Mullard Space Science Laboratory, UK
}

Correspondence to: M. Krol (maarten.krol@wur.nl)

Received: 5 October 2012 - Published in Atmos. Chem. Phys. Discuss.: 2 November 2012

Revised: 3 April 2013 - Accepted: 4 April 2013 - Published: 7 May 2013

\begin{abstract}
The fires around Moscow in July and August 2010 emitted a large amount of pollutants to the atmosphere. Here we estimate the carbon monoxide (CO) source strength of the Moscow fires in July and August by using the TM5-4DVAR system in combination with CO column observations of the Infrared Atmospheric Sounding Interferometer (IASI). It is shown that the IASI observations provide a strong constraint on the total emissions needed in the model. Irrespective of the prior emissions used, the optimised CO fire emission estimates from mid-July to mid-August 2010 amount to approximately $24 \mathrm{TgCO}$. This estimate depends only weakly $(<15 \%)$ on the assumed diurnal variations and injection height of the emissions. However, the estimated emissions might depend on unaccounted model uncertainties such as vertical transport. Our emission estimate of $22-27 \mathrm{TgCO}$ during roughly one month of intense burning is less than suggested by another recent study, but substantially larger than predicted by the bottom-up inventories. This latter discrepancy suggests that bottom-up emission estimates for extreme peat burning events require improvements.
\end{abstract}

\section{Introduction}

During the summer of 2010, numerous wildfires in European Russia severely impacted the air quality in a wide region around Moscow (Konovalov et al., 2011; Golitsyn et al., 2012; Fokeeva et al., 2011). The fires, which grew to dramatic proportions in late July, could be clearly observed from space (Witte et al., 2011) and the impact on the atmospheric composition was detected by several satellite instruments (Yurganov et al., 2011; Huijnen et al., 2012). As detailed in Fokeeva et al. (2011), in 2010 a large number of peat fires occurred mainly east of Moscow. Maximum daily mean carbon monoxide (CO) concentrations observed in Moscow reached $10 \mathrm{mg} \mathrm{m}^{-3}$ (ca. $10 \mathrm{ppm}$ ) (Konovalov et al., 2011) and the total column observed by a ground-based spectrometer in Moscow averaged to $7.45 \times 10^{18}$ molecules $\mathrm{cm}^{-2}$ over the period 2-9 August 2010 (Yurganov et al., 2011), which is more than three times the normal background column.

Several attempts have been made to estimate total $\mathrm{CO}$ emissions from the fires, both using bottom-up methods (Kaiser et al., 2012; Fokeeva et al., 2011), and inverse model calculations (Konovalov et al., 2011; Yurganov et al., 2011; Fokeeva et al., 2011). Although a comparison remains 
difficult due to the different spatial and temporal averaging, the estimates vary by a factor of four, ranging from 10 to $40 \mathrm{Tg}$ over the most intense fire period. Several factors may be responsible for the large range of estimates. Firstly, some studies use $\mathrm{CO}$ observations from satellite instruments to estimate emissions. Since all of these instruments measure in the thermal infrared part (TIR) of the spectrum, their sensitivity to surface $\mathrm{CO}$ is limited and a correction has to be applied under extremely polluted conditions (Yurganov et al., 2011; Fokeeva et al., 2011). This correction adds uncertainties to the emission estimates. Secondly, bottom-up methods based on burned-areas have difficulties with peat burning (van der Werf et al., 2010; Fokeeva et al., 2011). Finally, model uncertainties associated with emission heights and diurnal variations in emission strength may play a role. For instance, the Global Fire Assimilation System (GFAS1.0) (Kaiser et al., 2011; Huijnen et al., 2012) mentions small diurnal variation associated with peat-fire emissions, while Konovalov et al. (2011) imposed a strong diurnal cycle on their emissions. In this paper, we will quantify CO emissions from the 2010 Russian fires using a newly developed inversion system that optimises $\mathrm{CO}$ emissions using satellite observations. Since the sensitivity of the instrument (averaging kernel, AK) is applied as part of the observation operator in the model, no correction for the low sensitivity of the TIR satellite instrument for surface $\mathrm{CO}$ needs to be applied. Also, we explicitly test the sensitivity of the results for uncertainties in emission height and diurnal emission pattern.

\section{Method}

We use the 4DVAR version of the TM5 model (Krol et al., 2005, 2008; Meirink et al., 2008) that was recently applied to CO inversions as described in Hooghiemstra et al. (2012a). The system is adapted to this study in several ways. Firstly, previous applications of the TM5-4DVAR system all employed monthly optimisation periods. In view of the fast changes in the 2010 Moscow fire period, we optimise emissions in this study on a 3-day time-scale, and show a sensitivity inversion in which we optimise emissions on daily time scales. Secondly, we place a zoom region with a resolution of $3^{\circ} \times 2^{\circ}$ (longitude $\times$ latitude) over the entire boreal Eurasia, which embeds a zoom of $1^{\circ} \times 1^{\circ}$ around Moscow (see Fig. 1). Finally, we employ here an optimisation algorithm with a "semi-exponential" description of the probability density function (PDF) for the a priori emissions to avoid negative posterior emissions (Bergamaschi et al., 2010). We acknowledge that one disadvantage of this approach is the difficulty to obtain error estimates of the posterior emissions. However, by performing inversions with different prior emissions, emission heights and emission timings, we are still able to assess the robustness of the results.

The emissions are optimised by minimising the modelled differences with observations of the Infrared Atmospheric
Sounding Interferometer (IASI) that was launched in 2006 on board the METOP-A satellite (Clerbaux et al., 2009). IASI provides $\mathrm{CO}$ total columns and profiles twice a day in the TIR wavelength range. In this spectral range, the $\mathrm{CO}$ tropospheric column is usually measured with $10 \%$ accuracy or better (George et al., 2009). The presence of heavy smoke from fires could potentially lead to biases in IASI CO columns. Turquety et al. (2009) evaluated the quality of IASI retrievals for highly polluted conditions due to wildfires. They found that the measured $\mathrm{CO}$ enhancements were consistent with plume heights of biomass burning smoke. Although the signature from aerosols remains small in the $\mathrm{CO}$ bands measured by IASI, indirect effects through retrieved temperature and water vapour could still lead to biases. These biases are difficult to evaluate without specific independent observations in situations with high biomass burning smoke.

Each IASI measurement corresponds to a $12 \mathrm{~km}$ diameter footprint on the ground at nadir. We use measurements over boreal Eurasia (see Fig. 1) that have been processed with the Fast Optimal Retrievals on Layers for IASI (FORLI) algorithm (Hurtmans et al., 2012). The quality of the FORLI product has been analysed by Kerzenmacher et al. (2012). They found that the IASI CO total column products compare well with the co-located ground-based Fourier Transform Infrared (FTIR) total columns measured at the Network for the Detection of Atmospheric Composition Change (NDACC) and that there is no significant bias for the mean values at all stations.

FORLI-CO data v20100815 were downloaded from the Ether database (http://ether.ipsl.jussieu.fr) and only the measurements with "super quality flag $=0$ " have been selected with a solar zenith angle smaller than $90^{\circ}$. This leads to 201552 assimilated observations in July 2010, and another 192417 in August. As described by Hooghiemstra et al. (2012a), we inflate the errors given by the IASI retrievals by a factor $\sqrt{50}$ to account for spatial and temporal correlations in the high-density IASI observations. To test this setting further, we also present a sensitivity study in which the errors are inflated by a factor $\sqrt{150}$.

To compare TM5 with IASI observations, we first interpolate the modelled $\mathrm{CO}$ mixing ratios to the center location of the IASI measurement, and subsequently apply the IASI $\mathrm{AK}$. The AK is stored in the FORLI product, and is needed for a proper comparison of TIR satellite measurements and models (George et al., 2009). Apart from the IASI observations, measurements from the NOAA network are also assimilated. These more sparse measurements are used to anchor CO surface mixing ratios outside our study area. Very few NOAA observations are present in boreal Eurasia (16 of the 246 assimilated NOAA measurements in July and August 2010) and emission changes here will, therefore, be almost entirely driven by IASI observations.

The low sensitivity of the IASI instrument to surface CO implies that the emitted CO has to be lofted before it contributes to the model-observation mismatch that drives the 
4DVAR optimisation. By default, we use a height distribution that is retrieved from Advanced Along-Track Scanning Radiometer (AATSR) stereo-observations (see Appendix A). It turned out, however, that AATSR detected only very few emission events that had smoke plumes higher than the modelled planetary boundary layer (PBL) height. When no smoke plume detections are available, we distribute the emissions uniformly over the lowest $1000 \mathrm{~m}$ of our model domain. We also test the height distribution climatology derived for North America using observations of the Multi-angle Imaging SpectroRadiometer (MISR) instrument (Val Martin et al., 2010) (MERGED-CLIM in Table 1).

As a basis for our emission optimisation procedure, we start with different sets of prior emissions (see Table 1 and Appendix B). Firstly, prior $\mathrm{CO}$ emissions are calculated with the European Forest Fire Information System (EFFIS), which has been developed for the European region and refined for European Mediterranean conditions (scenarios MERGED and MERIS) and augmented with estimates for peat burning. Secondly, prior emissions from GFAS (Kaiser et al., 2012) and GFED3 (van der Werf et al., 2010) are used. We further perform the following sensitivity inversions: (i) emit all MERGED emissions according a climatological profile (Val Martin et al., 2010), (ii) optimise MERGED emissions on daily time scales (MERGED-DAILY), (iii) diurnal varying MERGED emissions based on time profiles presented in Konovalov et al. (2011) (MERGED-DIURNAL), and (iv) a higher inflation error on the IASI observations $(\sqrt{150}$ instead of $\sqrt{50}$, MERGED-INFLATE).

Over the boreal region, we only optimise biomass burning $\mathrm{CO}$ emissions. To account for other terms in the $\mathrm{CO}$ budget we also (i) add emissions due to fossil and biofuel usage (ii) add $\mathrm{CO}$ produced from non-methane hydrocarbons (iii) calculate the $\mathrm{OH}$ and surface deposition sinks for $\mathrm{CO}$. More details can be found in Appendix $\mathrm{C}$ and in Hooghiemstra et al. (2012a).

The study period runs from 1 July 2010 to 1 September 2010. The start CO field in 1 July 2010 is made consistent with the available IASI measurements by a spin-up emission optimisation from 15 June 2010 to 1 July 2010 . We will analyse emission totals summed over the most intense burning period from 16 July 2010 up to 17 August 2010 (33 days).

\section{Results}

Figure 1 shows IASI-measured and TM5-modelled columns of CO for 5 August 2010, a day on which Moscow (black circle) experienced heavy pollution. Although there are remaining discrepancies between model and measurements, this figure shows that the TM5 model with optimised MERGED emissions reliably reproduces the measured widespread $\mathrm{CO}$ enhancement east of Moscow. Modelled columns depend on the interplay between the emissions and subsequent transport, and obviously the 4DVAR system is able to calculate
Table 1. Prior and Posterior Emissions. Emissions are given in $\mathrm{Tg}$ CO and have been integrated from 16 July 2010 up to 17 August 2010. Region R1 is defined from $35^{\circ} \mathrm{E}$ to $45^{\circ} \mathrm{E}$, and from $53^{\circ} \mathrm{N}$ to $58^{\circ}$ N, see Fig. 3 and Konovalov et al. (2011). Region R2 is defined from $30^{\circ} \mathrm{E}$ to $70^{\circ} \mathrm{E}$, and from $46^{\circ} \mathrm{N}$ to $70^{\circ} \mathrm{N}$, see Fig. 3 .

\begin{tabular}{lrrrr}
\hline Simulation & Prior R1 & Poste R1 & Prior R2 & Poste R2 \\
\hline MERGED & 1.06 & 6.82 & 6.5 & 26.6 \\
MERIS & 0.86 & 7.29 & 3.9 & 24.0 \\
GFAS & 10.52 & 9.93 & 12.4 & 22.0 \\
GFED3 & 0.63 & 10.06 & 2.0 & 22.3 \\
MERGED-CLIM & 1.06 & 5.26 & 6.5 & 22.6 \\
MERGED-DAILY & 1.06 & 5.98 & 6.5 & 25.1 \\
MERGED-DIURNAL & 1.06 & 6.62 & 6.5 & 26.9 \\
MERGED-INFLATE & 1.06 & 6.98 & 6.5 & 26.8 \\
\hline
\end{tabular}

emission changes that lead to this favourable comparison with IASI. A perfect correspondence is not obtained, however, because we restrict emission changes, for example, by optimising on 3-daily timescales. Nevertheless, a good overall correspondence is illustrated in Fig. 2, which shows the IASI and modelled CO columns averaged daily over region R2 (outlined in the upper panel of Fig. 1). Modelled columns are shown for both the prior (dotted green line) and posterior MERGED emissions (solid green line) and clearly show that the prior emissions are too low to explain the IASI observations (in blue). Since the emission increments are driven by the prior mismatch between the prior model and IASI, the posterior emissions match the observations much better. A direct validation of the derived emissions is obtained by comparing the model simulation with prior and posterior emissions to non-assimilated observations from the Measurement of Pollution in the Troposphere (MOPITT) instrument. We compare to MOPITT V4 (Deeter et al., 2010) and sample the TM5 model fields using the AK stored in the MOPITT product (Hooghiemstra et al., 2012b). MOPITT measurements (black triangles in Fig. 2) agree reasonably well with IASI and remaining differences can be explained by different overpass times, sampling density and prior profile information (George et al., 2009). For instance, the drop in IASI on 31 July is due to the low number of valid observations on that day. In the relative unpolluted conditions before and after the main fire event, MOPITT observations show a slight positive offset compared to IASI, which might be due to differences in the prior profile (George et al., 2009). Validation with MOPITT clearly shows that the match between TM5 and MOPITT greatly improves upon assimilation of IASI observations, but that TM5 with optimised emissions (red triangles) systematically underestimates the MOPITT observations (black triangles). It is beyond the scope of this paper to ascribe this offset to biases in either MOPITT (Hooghiemstra et al., 2012b) or IASI and we note only that assimilation of MOPITT observations instead of IASI observations would likely lead to slightly higher posterior emission estimates. 


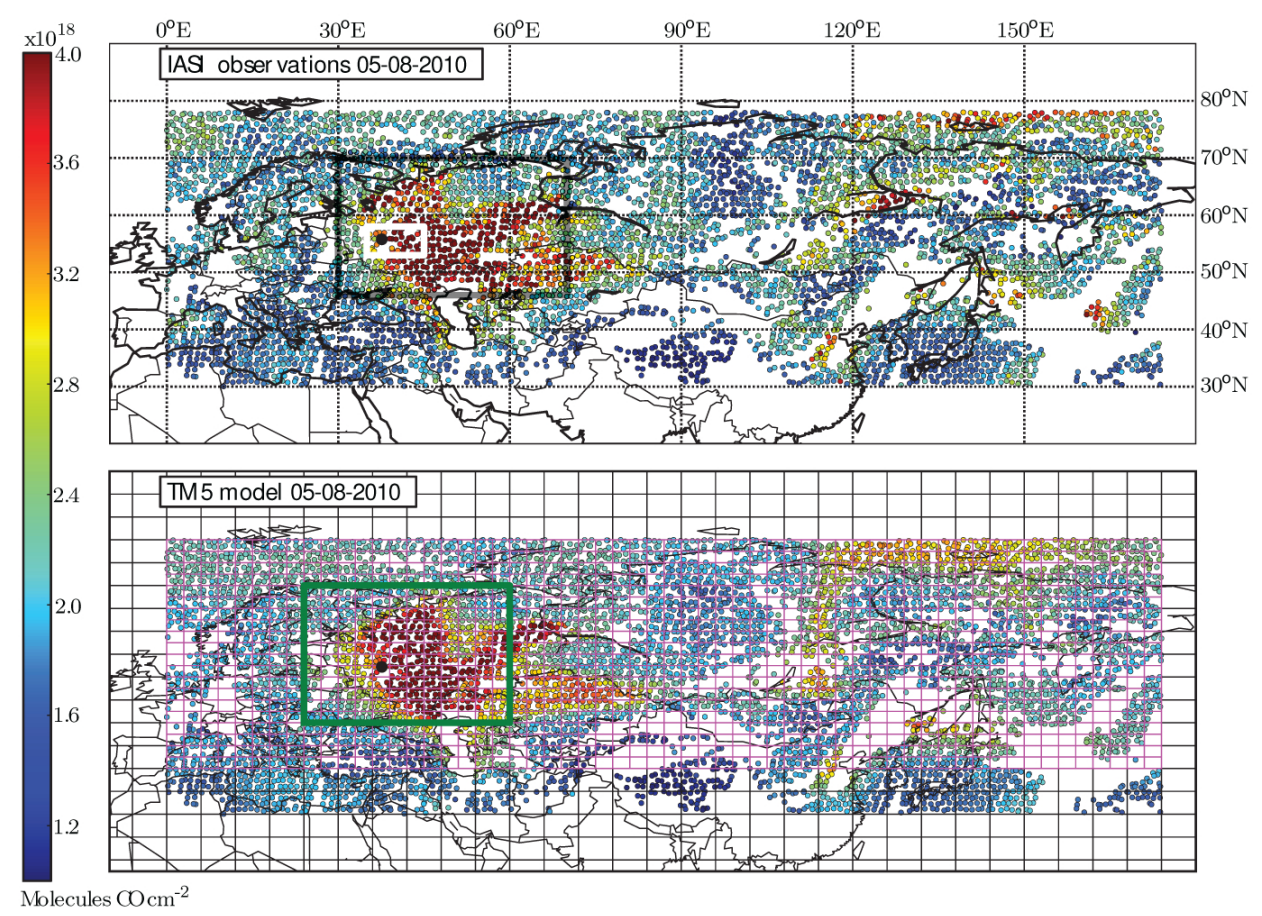

Fig. 1. Total CO columns for the 5 August 2010 as measured by IASI (upper panel) and calculated by the TM5 model with optimised emissions (lower panel), based on prior emission scenario MERGED (see Table 1). The lower panel shows the grid definition for this project. The black grid represents the global $6^{\circ} \times 4^{\circ}$ resolution, the light pink grid the $3^{\circ} \times 2^{\circ}$ region and a $1^{\circ} \times 1^{\circ}$ horizontal resolution is employed within the green square. The black circle indicates Moscow, and the coloured circles represent individual IASI observations. The white and black box in the upper panel refer to region R1 and R2, respectively, in Fig. 3 .

The prior and posterior MERGED emissions and the calculated emission changes are displayed in Fig. 3. Although the prior emissions show strong hotspots east of Moscow, emission strengths are by far insufficient to explain the IASI observations (see Fig. 2). Over a large area south and east of Moscow, up to 20-fold enhancements are required. Table 1 quantifies the prior and posterior emissions integrated over the heaviest burning period (16 July 2010 up to 17 August 2010). Totals are shown for the small (R1) and large (R2) regions displayed in Fig. 3. For R1, our optimisation increases the $\mathrm{CO}$ emissions from 1.06 to $6.82 \mathrm{Tg}$, and over R2 the increase is from 6.5 to $26.6 \mathrm{Tg}$, i.e., far outside the assigned uncertainties. These posterior emission estimates appear to be relatively robust, specifically on the larger spatial domain. Other prior emission sets with widely varying emissions and emission distributions result in posterior emissions that range from 5.3 to $10.1 \mathrm{Tg}$ in $\mathrm{R} 1$ and from 22.0 to $26.9 \mathrm{Tg}$ in $\mathrm{R} 2$. For instance, the GFAS prior emissions display a huge hot spot east of Moscow in region R1. The inversion scales down these emissions, but still increases the total emissions in R2, in line with the other prior emission sets.

Emitting the $\mathrm{CO}$ according to the MISR climatology (Val Martin et al., 2010) leads to lower emission estimates (about $4 \mathrm{Tg}$ less in R2, see MERGED-CLIM in Table 1), because the IASI instrument is more sensitive to lofted CO.
The strong diurnal variation in emissions that is applied in MERGED-DIURNAL has only a small impact on the posterior emission estimate. A somewhat larger effect is found from the optimisation of daily emissions (MERGEDDAILY), but the impact remains relatively modest. Finally, a larger inflation error on the IASI observations (MERGEDINFLATE) hardly affects the results. In conclusion, the posterior emission estimates obtained for the period of intense burning appear mainly sensitive to the applied prior emissions and the vertical emission distribution, but the impact remains smaller than $5 \mathrm{Tg}$ within region R2. Our emission estimate in region $\mathrm{R} 2$ based on IASI observations is, therefore, 22-27 Tg. As noted above, assimilation of MOPITT observations would likely lead to slightly higher estimates.

The temporal evolution of the total posterior emissions in R2 is displayed in Fig. 4. Again, results appear fairly robust. The low source magnitudes optimised with MERIS prior emissions at the end of July, when other prior sets optimise peak emissions, is caused by the low amount of detected fires by MERIS in this period. This leads to unrealistic zero prior emissions in the region of heavy burning (see dashed blue line in lower panel). This three-day period shows the largest spread in posterior emission estimates. The results of the daily emission optimisation (red triangles in upper panel) 


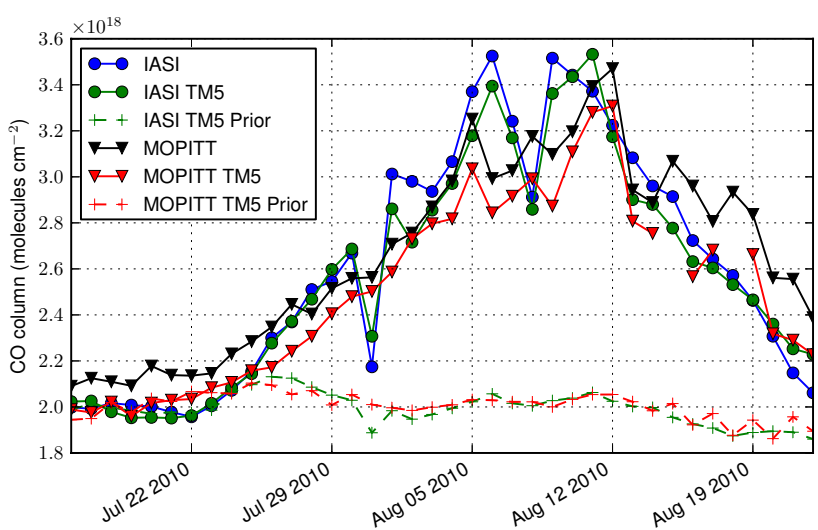

Fig. 2. Daily CO columns averaged over region R2 (see Fig. 1). The blue solid line refers to IASI, the green lines to model estimates cosampled with IASI using prior MERGED emissions (dashed), and posterior MERGED emissions (solid). The dashed red line (MOPITT TM5 prior) refers to the TM5 simulation with prior emissions co-sampled with non-assimilated MOPITT observations (black). The solid red line (MOPITT TM5) refers to the TM5 simulation with posterior emissions co-sampled with MOPITT observations.

show some scatter around the coarser temporal resolution results, but lead to comparable emissions when averaged.

\section{Discussion and conclusions}

The correspondence between IASI and the model simulation with optimised emissions (Fig. 2) shows large improvements compared to the simulation with prior emissions. This is expected, because IASI observations are used to drive emission changes. The remaining differences may have several causes. First, emissions are optimised on 3-daily time-scales, and are allowed to vary only within certain error estimates and only when prior emissions are non-zero. Second, the translation of emissions to modelled CO columns occurs on limited spatial resolution and is, thus, influenced by model errors. These latter may concern the emission process (emissions heights, temporal distribution), or the subsequent transport processes (convective redistribution, advection). On the larger scales (e.g., R2) small-scale mismatches are smoothed out and a favuorable comparison is found. On smaller scales the deviations between model and IASI can remain considerable after optimisation, as illustrated in Fig. 1.

Errors associated with the emission process have been assessed by sensitivity inversions and appear relatively modest. Based on the results presented in Table 1, we estimate that over region R2 about 24 (22-27) Tg CO was emitted by fires to the east and south of Moscow (Fig. 3). This relatively well-constrained amount is strongly driven by the IASI observations. This is confirmed by the sensitivity optimisation MERGED-INFLATE, in which the errors on the IASI data were significantly enlarged, but only a very small effect
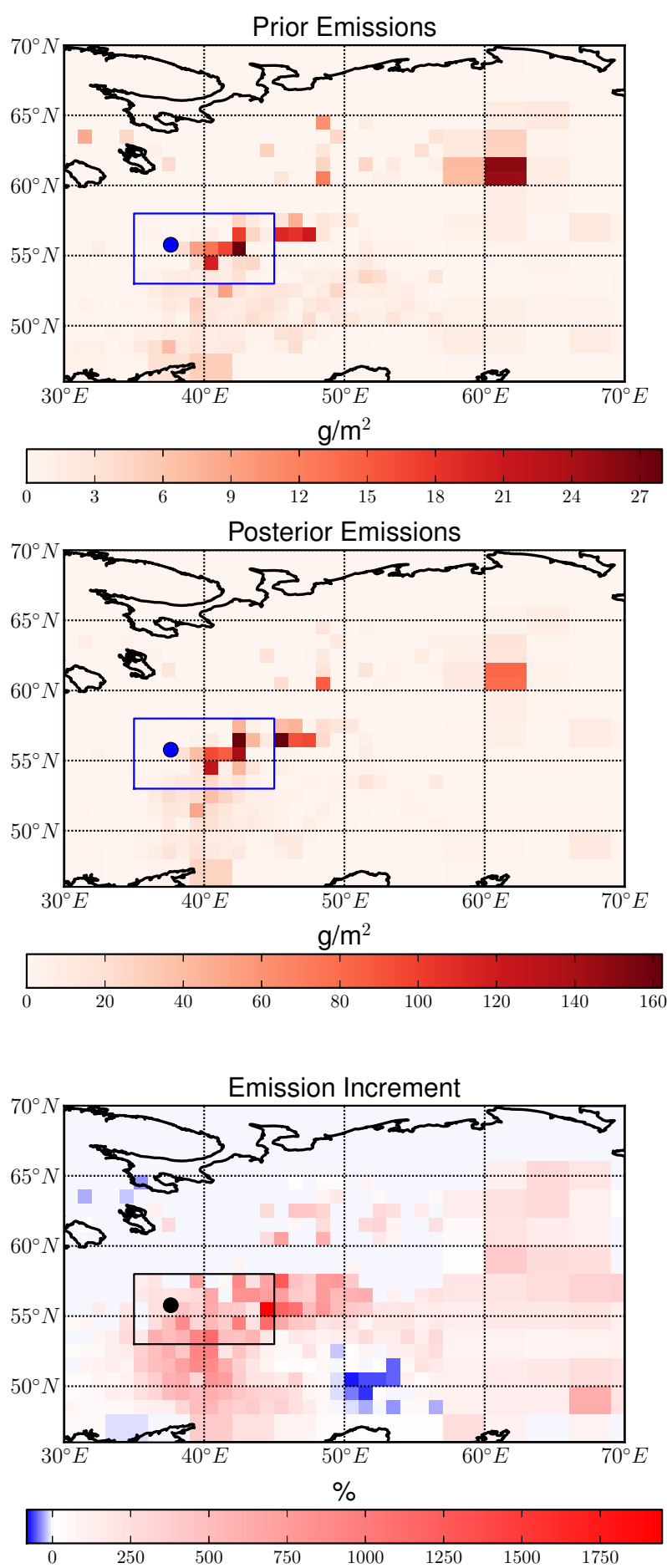

Fig. 3. Prior emissions (upper panel), posterior emissions (middle panel) and emission increment (lower panel) for the base inversion with MERGED emissions (see Table 1). Emissions and increments are based on the period 16 July 2010 up to 17 August 2010. The inset region is called $\mathrm{R} 1$ in Table 1 while the entire displayed region is referred to as $\mathrm{R} 2$. Note that a zoom region with higher resolution is present around Moscow (circle). 
on the optimised emissions is found. The small spread in our results should be interpreted with care, however, since structural model errors (advection, convection, resolution) have not been quantified and might lead to larger errors.

Prior emissions of all scenarios except for GFAS are biased significantly low, and have to be enhanced to match the satellite observations. The reason for this underestimate is most likely the wide-spread peat burning east of Moscow that is hard to account for using either the burnt scar or fire radiative power approach (Kaiser et al., 2012; Fokeeva et al., 2011; Konovalov et al., 2011). The high bias of the GFAS prior in region R1 (see green dotted line in Fig. 4) is probably caused by its quality control, which blacklists all observations on the day after the largest fire peak on 29 July. Since GFAS assumes persistence, the high emissions on 29 July are copied to the next day, leading to a high prior estimate.

The essence of our approach is a model-calculated relation between emissions and simulated satellite observations. In the comparison to true observations, the height sensitivity of the satellite data $(\mathrm{AK})$ is taken into account in the observation operator. Yurganov et al. (2011) attempted to correct satellite data from different sounders using information from ground-based spectrometers and subsequently used a boxmodel inversion to estimate $\mathrm{CO}$ emissions of $34-40 \mathrm{Tg}$ in July and August 2010. Although the considered area in that study is slightly larger, the amount estimated is significantly higher than ours. We compare the output of our simulations with optimised emissions to the ground-based measurements presented in Yurganov et al. (2011). For a fair comparison, we average over the period from the 2-9 August and apply the surface grating AK that puts more weight on the model levels close to the surface (Yurganov et al., 2011). We find a mean CO column of $6.4 \times 10^{18}$ molecules $\mathrm{cm}^{-2}$ for the grid centre $\left(55.5^{\circ} \mathrm{N}, 36.5^{\circ} \mathrm{E}\right)\left(5.4 \times 10^{18}\right.$ molecules $\mathrm{cm}^{-2}$ without taking into account the grating $\mathrm{AK}$ ). This is very close to the $6.3 \times 10^{18}$ molecules $\mathrm{cm}^{-2}$ presented by Yurganov et al. (2011), indicating that the modelled total vertical columns are in good correspondence with observation. Emissions of 34-40 Tg would, therefore, lead to an overestimate of the surface grating data. Yurganov et al. (2011) applied corrections to the satellite data and subsequently extrapolated these to a larger area based on a $500 \mathrm{hPa}$ concentration threshold of the satellite data. We speculate that this procedure led to an overestimate of the emissions presented in Yurganov et al. (2011).

Much lower CO emissions (in total about $10 \mathrm{Tg}$ ) were estimated by Konovalov et al. (2011), who used surface CO measurements collected during the fires in Moscow to scale above-ground and peat burning emissions in the regional CHIMERE chemistry-transport model. Their "all-fire" estimate for July and August 2010 for Central European Russia (our region $\mathrm{R} 1$ ) amounts to $6.22 \mathrm{Tg}$, which is similar to the totals over the peak fire period only that we present in Table 1. Figure 5, upper panel, shows the daily-averaged concentrations interpolated at the model surface to the lo-
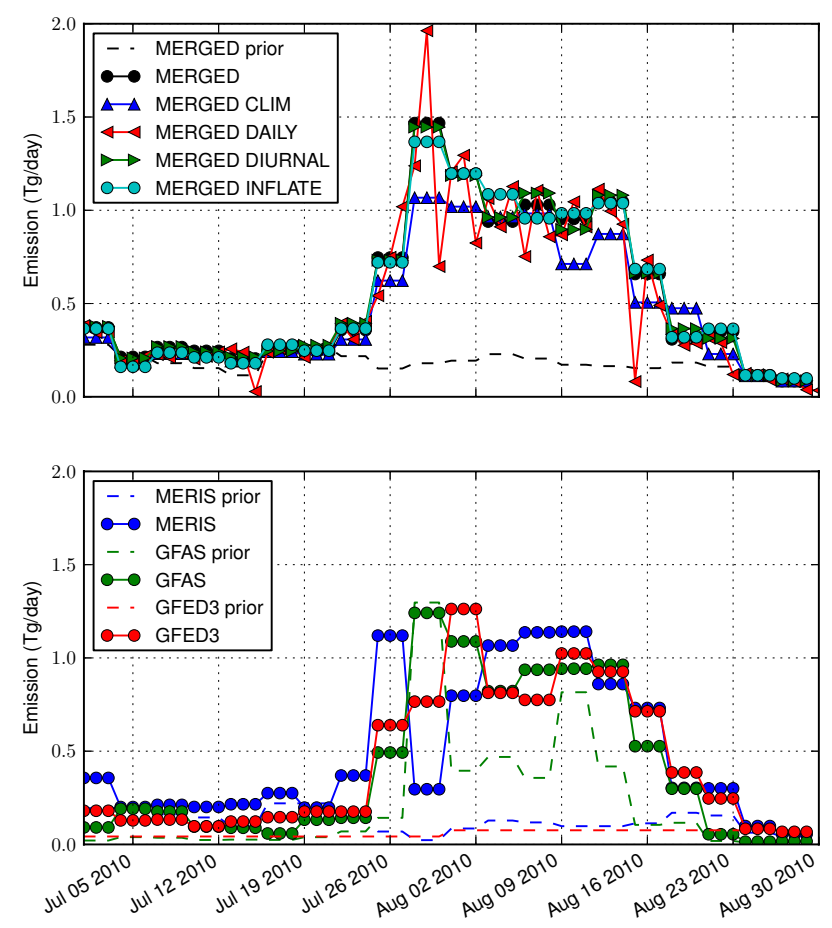

Fig. 4. Time variations of the prior and posterior emission estimates integrated over region R2 displayed in Fig. 3. The upper panel shows the MERGED prior and posterior emissions (see Table 1). The bottom panel shows prior and posterior emissions for scenarios MERIS, GFAS and GFED3 (see Table 1). Results for the three-daily periods are shown as three identical daily estimates.

cation of the MSU station in Moscow $\left(55.71^{\circ} \mathrm{N}, 37.52^{\circ} \mathrm{E}\right)$. We show results obtained with prior and posterior MERGED emissions and compare to the available observations. As expected, we observe strong increases in surface concentrations when optimised emissions are used. However, maximum concentrations of more than $10 \mathrm{ppm}$ were measured on 7 August 2010, while Golitsyn et al. (2012) show measurements for stations in and around Moscow with values up to $40 \mathrm{ppm}$. Although the timing of the pollution events is in good correspondence with observations, our calculated maxima are much lower. We attribute this model underestimate to the relatively coarse resolution of our model. Modelled concentrations east of Moscow reach as high as $50 \mathrm{ppm}$ over the most intense fires. Accounting for accurate transport of these polluted airmasses to Moscow would require a higher model resolution. Another possible factor is the overestimate of the daytime vertical mixing in the model. The observed depth of Moscow's daytime convective planetary boundary layer (PBL) typically reaches $1000-1500 \mathrm{~m}$ in this period (Elansky et al., 2011), while values reported by the European Centre for Medium Range Weather Forecasts (ECMWF) model are typically 2000-3000 m. Since meteorological data from the ECWMF model drive TM5, this points to an overly excessive daytime redistribution of the surface emissions. The 

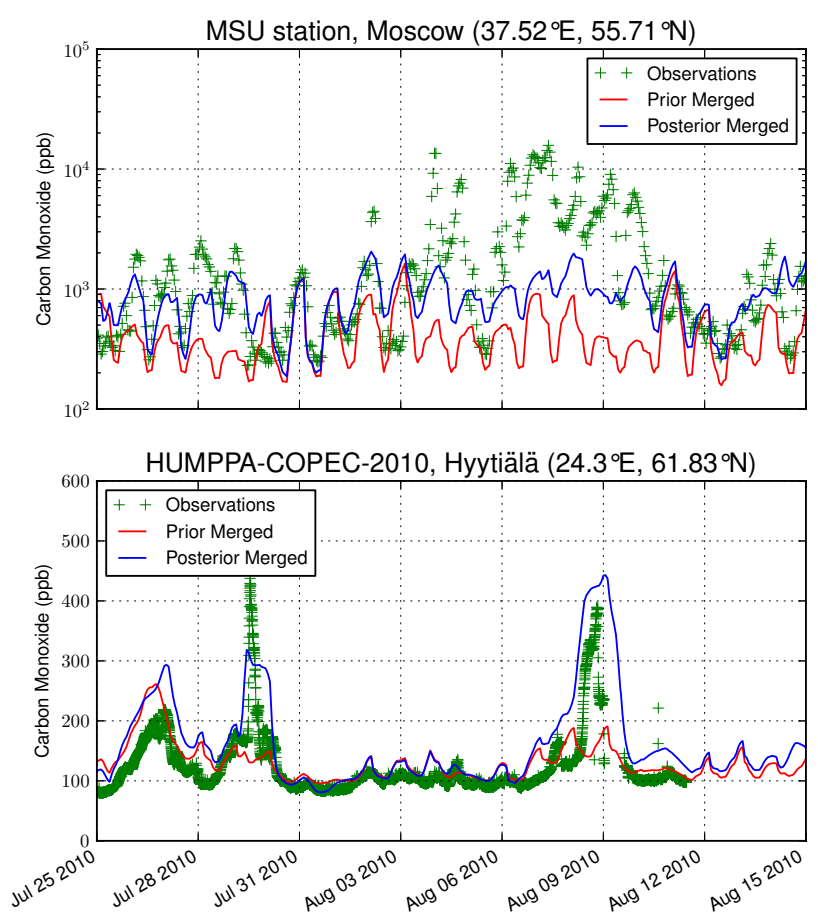

Fig. 5. Modelled and observed CO mixing ratios at the MSU station in Moscow (upper panel, logarithmic y-axis) and in Hyytiälä, Finland (lower panel, normal y-axis). The red line denotes the TM5 simulation with prior MERGED emissions (see Table 1). The blue line denotes the TM5 model simulation with optimised MERGED emissions. Green symbols are the observations.

heavy smoke associated with the fires most likely reduced the surface shortwave radiation and may have led to substantial heating of the overlying atmosphere by radiation absorption (Yu et al., 2002; Elansky et al., 2011). These factors may have led to a more stable stratification of the PBL than simulated with the ECMWF model, because the smoke associated with fires in the lower atmosphere is not directly taken into account by that model.

Another validation of our approach comes from a comparison with $\mathrm{CO}$ mixing ratios measured during the HUMPPACOPEC-2010 campaign in Hyytiälä, Finland (Fig. 5, lower panel). Although this station is located at considerable distance from the main fire activity, several clear signatures of biomass burning were observed during the campaign (Williams et al., 2011). The TM5 model using optimised emissions does an very good job in simulating both the timing and magnitude of the CO biomass burning enhancements. Note again that these measurement data were not used to optimise the emissions.

We argued above that the vertical mixing in the model may have been systematically overestimated, since the radiative effects of smoke are not considered in the driving ECMWF model. Since the IASI instrument lacks sensitivity to the surface $\mathrm{CO}$, a too strong vertical mixing would imply an under- estimate in the emissions. The region of heavy smoke, however, remains small compared to the area over which we assimilate IASI observations. Given the long lifetime of CO, higher emissions would deteriorate the match with satellite observations outside the region of heavy smoke, after transport and lifting of the CO plume. Nevertheless, the effect of heavy smoke on atmospheric transport deserves further attention in future studies.

\section{Appendix A}

\section{Methods for automated smoke plume injection height retrieval from AATSR}

Smoke Plume Injection Heights (SPIH) are calculated by applying a stereo-photogrammetric method to AATSR imagery. The dual view imaging geometry of the instrument allows for stereo height reconstruction, and has already been exploited in the determination of cloud top height, using the M4 stereo matching algorithm (Muller et al., 2007). For the determination of SPIH, a modified M4 algorithm, referred to as M6, has been developed (see Fisher et al., 2012). Here M6 and the processing chain are briefly described and an example product is shown. M6 is modified in both the normalisation and matching stages, although in principle it remains close to other window-based techniques, such as M4. M6 shares some similarities to variable window techniques (Veksler, 2003; Kanade and Okutomi, 1994), which modify the window shape over which the matching cost is calculated. This leads to improved performance in the presence of discontinuities, i.e., changes of disparity, where traditional window based matchers tend to perform poorly. This is particularly important in the determination of SPIH; as traditional window based matchers tend to smooth over disparities leading to the loss of smaller disparity features such as smoke plumes. M6s modification involves using a subset of the pixels from the local neighbourhood determined by similarity to the pixel of interest, in both the normalisation and the matching stages. A processing chain for the generation of the AATSR SPIH dataset has been developed using the Java based BEAM visualisation toolkit (http:// www.brockmann-consult.de/cms/web/beam/). The processing chain outputs pixel level accuracy SPIHs using the algorithm described above and from this product, Smoke Plume Masks (SPMs). The key stages of the processing chain can be summarised as follows: firstly, the AATSR product is read in and the relevant spectral bands are selected $(0.55 \mu \mathrm{m}$ Forward and Nadir, $0.87 \mu \mathrm{m}$ Nadir, $1.6 \mu \mathrm{m}$ Nadir and $12 \mu \mathrm{m}$ Nadir), in addition to this the ancillary data are also ingested (geo-referencing information, digital elevation model, camera model, co-registration correction coefficients). Once the products have been ingested, the $12 \mu \mathrm{m}$ forward channel is used to generate a cloud mask using a thermal threshold. This cloud mask is morphologically eroded and applied to 


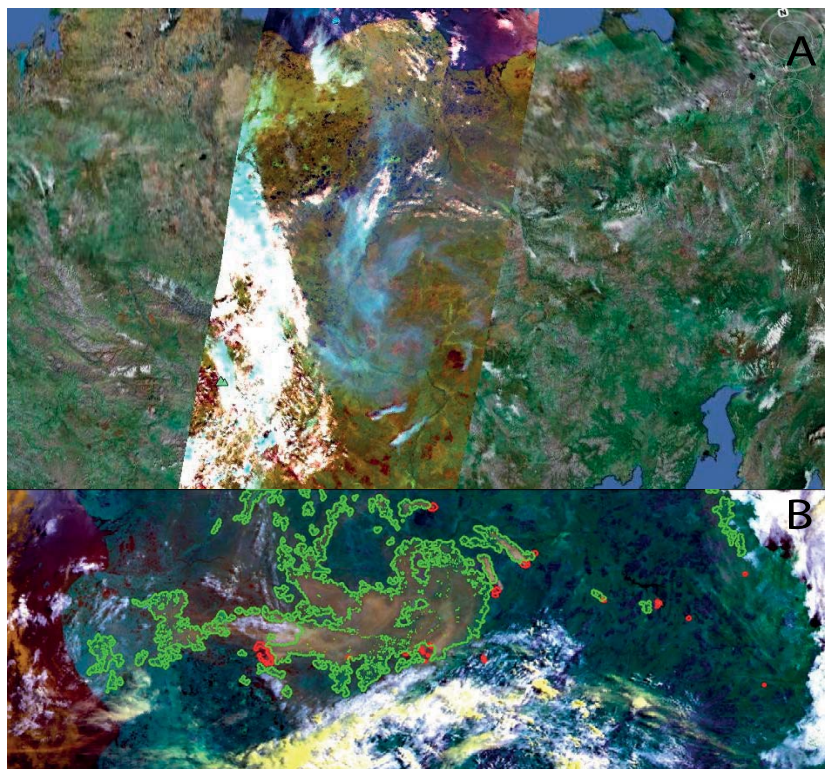

Fig. A1. (A) Context Image showing Google Earth background and AATSR superimposed on top. AATSR image acquired 20 July 2010 at 01:07:53 UTC. (B) AATSR false colour composite showing SPM boundary (green) and MODIS FIRMS fire location (red). Image rotated counter-clockwise with respect to (A) with north at left.

the $0.55 \mu \mathrm{m}$ channel prior to stereo processing to remove all cloud features. Once masked, M6 is applied to the forward and nadir $0.55 \mu \mathrm{m}$ channels to generate a digital disparity model, which is then converted into a height map using the instrument camera model (Muller et al., 2007). The heights are then compared with the digital elevation model and anything $1 \mathrm{~km}$ above the land surface is tentatively set to a smoke plume in the SPM. Lastly, two reflectance thresholds are applied to the possible smoke features to remove any false positives. The masked SPIH is then written out in netCDF format with additional layers, including: MODIS fire radiative energy; an RGB browse product; and a red-cyan stereo anaglyph. The entire processing chain and the algorithms applied are described in detail in Fisher et al. (2012). An example of the output is shown in Fig. A1 along with the location of the AATSR strip in Eastern Siberia.

\section{Appendix B}

\section{Emissions}

\section{B1 Prior emission estimates}

The European Forest Fire Information System (EFFIS) calculates emissions based on an intersection of detected burned areas with fuel type datasets. It applies specific emission factors to each fuel type and assumes that the vegetation burns completely, without taking the temporal dimension into ac- count. The EFFIS methodology has been validated and compared to emissions estimates from other models developed in the United States and Europe (Barbosa et al., 2009). In this study, burned areas have been detected using the MEdium Resolution Imaging Spectrometer (MERIS) and the Moderate Resolution Imaging Spectroradiometer (MODIS). We use prior emissions based on MERIS (scenario MERIS), and emissions that are based on a merger between MODIS and MERIS (scenario MERGED, see next section). Special calculations are performed to estimate $\mathrm{CO}$ emissions from peat fires. All burnt area pixels mapped using the MERIS and/or MODIS imagery were intersected with the JRC Eurasian soils map (Jones et al., 2005). The above and below ground $\mathrm{CO}$ emissions were computed for the subset of pixels that were located on peat or histic (organic) soils. An emission factor of $5.3 \mathrm{kgCOm}^{-2}$ was applied to these pixels, based on the results of Turquety et al. (2007). The total CO emissions for a burned-area pixel located on peat soil, was the sum total of the emissions from the peat plus the emissions computed from the landcover. It is important to note that neither the depth nor duration of the peat fires were modelled within the EFFIS emissions model. The Global Fire Assimilation System (GFAS) system has been described in Kaiser et al. (2012) and is applied in Huijnen et al. (2012). These daily emission maps account for the assumed heavy peat burning east of Moscow by including a peat map for Russia in combination with observations of fire radiative power (FRP). The Global Fire Emission Database (GFED3) emissions used in this study are monthly averages that have been obtained as described in van der Werf et al. (2010). In the optimisation of the $\mathrm{CO}$ emissions, we assign prior errors of $250 \%$ to the grid-cell emissions. As a result, the inversion cannot assign emissions to grid cells in which prior emissions are zero. The idea behind the MERGED scenario is, therefore, to give the system freedom to place emissions in grid cells where some kind of fire activity has been detected by either MERIS or MODIS.

\section{B2 Merger of MODIS and MERIS emissions}

Emissions are calculated based on Burned Area (BA) detection using the methodology of the European Forest Fire Information System (EFFIS) (see above). BA is detected by using information from either the MERIS (MEdium Resolution Imaging Spectrometer) instrument or the MODIS (Moderate Resolution Imaging Spectroradiometer) instrument. Since both instruments have different spectral and spatial resolutions, different overpass times, and employ different atmospheric correction schemes, BAs detected by these instruments may differ considerably. To test the sensitivity of our inversion system to uncertainties in the prior emission inventories, we employ one set of emissions in which we merge the information of the two instruments. First we bin the emissions of both instruments on a $0.1 \times 0.1$ degree latitude longitude grid. Then we take the average of the emission 
estimates in case both instruments detected BA. If only one of the two instruments detects BA, that emission estimate is used as prior information. Note that the MERGED prior emission estimate in Table 1 of the main paper is higher than the MERIS estimate, because MODIS detects additional BA. More specifically, it was found that the MERIS BA detection was hampered by heavy smoke during the Moscow fires, as can be noted in Fig. 4 of the main paper.

\section{B3 Merger of the smoke plume injection heights and emissions}

Before ingestion in the TM5 model, emissions and SPIH data are convolved to produce emission fields on the TM5 resolution $\left(1^{\circ} \times 1^{\circ}\right.$ over the zoom area in Fig. 1 of the main paper, $3^{\circ} \times 2^{\circ}$ over the entire boreal area). In a first step the emission and SPIH data are binned on a $0.1^{\circ} \times 0.1^{\circ}$ latitude $\times$ longitude grid. For the SPIH data, we acknowledge that many individually retrieved profiles often cover one such $0.1^{\circ} \times 0.1^{\circ}$ gridbox during one day and we, thus, construct a vertical distribution function over $500 \mathrm{~m}$ altitude bins that describes the fraction of all smoke that is emitted as a function of height. If no SPIH data is available for a grid cell in which emissions are present, the MERGER or MERIS emissions (see Table 1) are distributed evenly in the lowest $1000 \mathrm{~m}$. As a final step, emissions and SPIH are combined to calculate the 3-D emission distribution on the TM5 grid.

\section{Appendix C}

\section{Optimisation details}

Emissions are optimised on the grid scale of the model. To limit the degrees of freedom, horizontal and temporal correlations are assumed for the prior emissions (Meirink et al., 2008). On the global $6^{\circ} \times 4^{\circ}$ resolution, one weeklyvarying emission category is optimised, with an assumed spatial correlation length of $1000 \mathrm{~km}$, and a temporal correlation time of 9.5 months. In the boreal zoom regions, only biomass burning emissions are optimised on the grid resolution, with an assumed spatial correlation length of $200 \mathrm{~km}$, and a temporal correlation of 0.1 month. The biomass burning emissions are optimised on a three-day resolution (except for a sensitivity study with a daily resolution). Emissions from the atmospheric oxidation of non-methane hydrocarbons and anthropogenic $\mathrm{CO}$ emissions are kept fixed. The anthropogenic emissions in the $3^{\circ} \times 2^{\circ}$ boreal region were 6.0 Tg CO month ${ }^{-1}$ in July and August 2010. The emissions from the oxidation of non-methane hydrocarbons were 8.9 and $6.3 \mathrm{Tg} \mathrm{CO}$ month $^{-1}$ in July and August 2010 , respectively. In the $1^{\circ} \times 1^{\circ}$ zoom region (see Fig. 1) the anthropogenic emissions were $1.1 \mathrm{Tg} \mathrm{CO}$ month $^{-1}$ and the non-methane hydrocarbon emissions were 1.5 and 1.0 Tg CO month ${ }^{-1}$ in July and August 2010, respectively.
A prior error of $250 \%$ on the grid scale is assumed. A semi-exponential description of the probability density function (PDF) for the a priori emissions is used to avoid negative posterior emissions (Bergamaschi et al., 2010). Due to the nonlinearities of this approach, the cost function was minimised with the m1qn3 algorithm from Gilbert and Lemaréchal (1989) instead of using the more efficient conjugate gradient method.

Acknowledgements. The authors would like to acknowledge the European Space Agency (ESA) for the funding through the Atmosphere-LANd Integrated Study (ALANIS) and the Dutch National Computing Facilities Foundation (NCF) for the use of supercomputer facilities. NOAA is acknowledged for the use CO observations from the surface network. Guido van der Werf is acknowledged for providing the GFED data. The GFAS work is funded by the MACC project, contract number 218793 in the EU Seventh Research Framework Programme. The MOPITT data were obtained from the Atmospheric Science Data Center at the NASA Langley Research Center. IASI was developed and built under the responsibility of CNES and flies onboard the MetOp satellite as part of the Eumetsat Polar system. The authors acknowledge the Ether French atmospheric database (http://ether.ipsl.jussieu.fr) for distributing the IASI L1C and L2-CO data. We acknowledge Rainer Königstedt and Horst Fischer for the $\mathrm{CO}$ data from the HUMPPA-COPEC-2010 campaign. CO measurements from the Moscow station were kindly provided by Alex Safronov.

Edited by: M. Kanakidou

\section{References}

Barbosa, P., Camia, A., Kucera, J., Palumbo, I., San-MiguelAyanz, J., and Schmuck, G.: Assessment of Forest Fires Impact and Emissions in the European Union Based on the European Forest Fire Information System, in: Wildland Fires and Air Pollution, edited by: Bytnerowicz, A., Arbauch, M., Riebau, A., and Andersen, C., Amsterdam (the Netherlands), Elsevier, 2009.

Bergamaschi, P., Krol, M., Meirink, J. F., Dentener, F., Segers, A., van Aardenne, J., Monni, S., Vermeulen, A. T., Schmidt, M., Ramonet, M., Yver, C., Meinhardt, F., Nisbet, E. G., Fisher, R. E., O'Doherty, S., and Dlugokencky, E. J.: Inverse modeling of European $\mathrm{CH}_{4}$ emissions 2001-2006, J. Geophys. Res., 115, D22309, doi:10.1029/2010JD014180, 2010.

Clerbaux, C., Boynard, A., Clarisse, L., George, M., Hadji-Lazaro, J., Herbin, H., Hurtmans, D., Pommier, M., Razavi, A., Turquety, S., Wespes, C., and Coheur, P.-F.: Monitoring of atmospheric composition using the thermal infrared IASI/MetOp sounder, Atmos. Chem. Phys., 9, 6041-6054, doi:10.5194/acp-9-6041-2009, 2009.

Deeter, M. N., Edwards, D. P., Gille, J. C., Emmons, L. K., Francis, G., Ho, S. P., Mao, D., Masters, D., Worden, H., Drummond, J. R., and Novelli, P. C.: The MOPITT version 4 CO product: algorithm enhancements, validation, and long-term stability, J. Geophys. Res., 115, D07306, doi:10.1029/2009JD013005, 2010. 
Elansky, N. F., Mokhov, I. I., Belikov, I. B., Berezina, E. V., Elokhov, A. S., Ivanov, V. A., Pankratova, N. V., Postylyakov, O. V., Safronov, A. N., Skorokhod, A. I., and Shumskii, R. A.: Gaseous admixtures in the atmosphere over Moscow during the 2010 summer, Izv. Atmos. Ocean. Phys., 47, 672-681, doi:10.1134/S000143381106003X, 2011.

Fisher, D., Muller, J.-P., and Yershov, V. N.: Automated Stereo Retrieval of Smoke Plume Injection Heights and Retrieval of Smoke Plume Masks from AATSR and their Assessment With CALIPSO and MISR, Geoscience and Remote Sensing, IEEE Transactions on, 99, 1, doi:10.1109/TGRS.2013.2249073, 2012.

Fokeeva, E. V., Safronov, A. N., Rakitin, V. S., Yurganov, L. N., Grechko, E. I., and Shumskii, R. A.: Investigation of the 2010 July-August fires impact on carbon monoxide atmospheric pollution in Moscow and its outskirts, estimating of emissions, Izv. Atmos. Ocean. Phys., 47, 682-698, 2011.

George, M., Clerbaux, C., Hurtmans, D., Turquety, S., Coheur, P.F., Pommier, M., Hadji-Lazaro, J., Edwards, D. P., Worden, H., Luo, M., Rinsland, C., and McMillan, W.: Carbon monoxide distributions from the IASI/METOP mission: evaluation with other space-borne remote sensors, Atmos. Chem. Phys., 9, 8317-8330, doi:10.5194/acp-9-8317-2009, 2009.

Gilbert, J. C. and Lemaréchal, C.: Some numerical experiments with variable-storage quasi-Newton algorithms, Math. Program., 45, 407-435, doi:10.1007/BF01589113, 1989.

Golitsyn, G. S., Gorchakov, G. I., Grechko, E. I., Semoutnikova, E. G., Rakitin, V. S., Fokeeva, E. V., Karpov, A. V., Kurbatov, G. A., Baikova, E. S., and Safrygina, T. P.: Extreme carbon monoxide pollution of the atmospheric boundary layer in Moscow region in the summer of 2010, Dokl. Earth Sci., 441, 1666-1672, 2012.

Hooghiemstra, P. B., Krol, M. C., Bergamaschi, P., de Laat, A. T. J., van der Werf, G. R., Novelli, P. C., Deeter, M. N., Aben, I., and Rockmann, T.: Comparing optimised $\mathrm{CO}$ emission estimates using MOPITT or NOAA surface network observations, J. Geophys. Res., 117, D06309, doi:10.1029/2011JD017043, 2012a.

Hooghiemstra, P. B., Krol, M. C., van Leeuwen, T. T., van der Werf, G. R., Novelli, P. C., Deeter, M. N., Aben, I., and Röckmann, T.: Interannual variability of carbon monoxide emission estimates over South America from 2006 to 2010, J. Geophys. Res., 117, D15308, doi:10.1029/2012JD017758, 2012b.

Huijnen, V., Flemming, J., Kaiser, J. W., Inness, A., Leitão, J., Heil, A., Eskes, H. J., Schultz, M. G., Benedetti, A., Hadji-Lazaro, J., Dufour, G., and Eremenko, M.: Hindcast experiments of tropospheric composition during the summer 2010 fires over western Russia, Atmos. Chem. Phys., 12, 4341-4364, doi:10.5194/acp12-4341-2012, 2012.

Hurtmans, D., Coheur, P.-F., Wespes, C., Clarisse, L., Scharf, O., Clerbaux, C., Hadji-Lazaro, J., George, M., and Turquety, S.: FORLI radiative transfer and retrieval code for IASI, J. Quant. Spectrosc. Ra., 113, 1391-1408, 2012.

Jones, A., Montanarella, L., and Jones, R.: Soil atlas of Europe, European Soil Bureau Network, European Commission, 2005.

Kaiser, J. W., Benedetti, A., Flemming, J., Morcrette, J. J., Heil, A., Schultz, M. G., van der Werf, G. R., and Wooster, M. J.: From fire observations to smoke plume forecasting in the MACC services, in: Proceedings of Earth Observation for Land-Atmosphere Interaction Science, Frascati, Italy, 3-5 November 2010, European Space Agency, SP-688, 2011.
Kaiser, J. W., Heil, A., Andreae, M. O., Benedetti, A., Chubarova, N., Jones, L., Morcrette, J.-J., Razinger, M., Schultz, M. G., Suttie, M., and van der Werf, G. R.: Biomass burning emissions estimated with a global fire assimilation system based on observed fire radiative power, Biogeosciences, 9, 527-554, doi:10.5194/bg-9-527-2012, 2012.

Kanade, T. and Okutomi, M.: A stereo matching algorithm with an adaptive window: theory and experiment, IEEE T. Pattern Anal., 16, 920-932, 1994.

Kerzenmacher, T., Dils, B., Kumps, N., Blumenstock, T., Clerbaux, C., Coheur, P.-F., Demoulin, P., García, O., George, M., Griffith, D. W. T., Hase, F., Hadji-Lazaro, J., Hurtmans, D., Jones, N., Mahieu, E., Notholt, J., Paton-Walsh, C., Raffalski, U., Ridder, T., Schneider, M., Servais, C., and De Mazière, M.: Validation of IASI FORLI carbon monoxide retrievals using FTIR data from NDACC, Atmos. Meas. Tech., 5, 2751-2761, doi:10.5194/amt5-2751-2012, 2012.

Konovalov, I. B., Beekmann, M., Kuznetsova, I. N., Yurova, A., and Zvyagintsev, A. M.: Atmospheric impacts of the 2010 Russian wildfires: integrating modelling and measurements of an extreme air pollution episode in the Moscow region, Atmos. Chem. Phys., 11, 10031-10056, doi:10.5194/acp-11-10031-2011, 2011.

Krol, M., Houweling, S., Bregman, B., van den Broek, M., Segers, A., van Velthoven, P., Peters, W., Dentener, F., and Bergamaschi, P.: The two-way nested global chemistry-transport zoom model TM5: algorithm and applications, Atmos. Chem. Phys., 5, 417432, doi:10.5194/acp-5-417-2005, 2005.

Krol, M. C., Meirink, J. F., Bergamaschi, P., Mak, J. E., Lowe, D., Jöckel, P., Houweling, S., and Röckmann, T.: What can ${ }^{14} \mathrm{CO}$ measurements tell us about $\mathrm{OH}$ ?, Atmos. Chem. Phys., 8, 50335044, doi:10.5194/acp-8-5033-2008, 2008.

Meirink, J. F., Bergamaschi, P., and Krol, M. C.: Fourdimensional variational data assimilation for inverse modelling of atmospheric methane emissions: method and comparison with synthesis inversion, Atmos. Chem. Phys., 8, 6341-6353, doi:10.5194/acp-8-6341-2008, 2008.

Muller, J.-P., Denis, M.-A., Dundas, R. D., Mitchell, K. L., Naud, C., and Mannstein, H.: Stereo cloud-top heights and cloud fraction retrieval from ATSR-2, Int. J. Remote Sens., 28, 19211938, 2007.

Turquety, S., Logan, J. A., Jacob, D. J., Hudman, R. C., Leung, F. Y., Heald, C. L., Yantosca, R. M., Wu, S., Emmons, L. K., Edwards, D. P., and Sasche, G. W.: Inventory of boreal fire emissions for North America in 2004: Importance of peat burning and pyroconvective injection, J. Geophys. Res., 112, D12S03, doi:10.1029/2006JD007281, 2007.

Turquety, S., Hurtmans, D., Hadji-Lazaro, J., Coheur, P.-F., Clerbaux, C., Josset, D., and Tsamalis, C.: Tracking the emission and transport of pollution from wildfires using the IASI CO retrievals: analysis of the summer 2007 Greek fires, Atmos. Chem. Phys., 9, 4897-4913, doi:10.5194/acp-9-4897-2009, 2009.

Val Martin, M., Logan, J. A., Kahn, R. A., Leung, F.-Y., Nelson, D. L., and Diner, D. J.: Smoke injection heights from fires in North America: analysis of 5 years of satellite observations, Atmos. Chem. Phys., 10, 1491-1510, doi:10.5194/acp-10-14912010, 2010.

van der Werf, G. R., Randerson, J. T., Giglio, L., Collatz, G. J., Mu, M., Kasibhatla, P. S., Morton, D. C., DeFries, R. S., Jin, Y., and van Leeuwen, T. T.: Global fire emissions and the contribution of 
deforestation, savanna, forest, agricultural, and peat fires (19972009), Atmos. Chem. Phys., 10, 11707-11735, doi:10.5194/acp10-11707-2010, 2010.

Veksler, O.: Fast variable window for stereo correspondence using integral images, Comput. Vision Pattern Recog., 1, 556-564, 2003.

Williams, J., Crowley, J., Fischer, H., Harder, H., Martinez, M., Petäjä, T., Rinne, J., Bäck, J., Boy, M., Dal Maso, M., Hakala, J., Kajos, M., Keronen, P., Rantala, P., Aalto, J., Aaltonen, H., Paatero, J., Vesala, T., Hakola, H., Levula, J., Pohja, T., Herrmann, F., Auld, J., Mesarchaki, E., Song, W., Yassaa, N., Nölscher, A., Johnson, A. M., Custer, T., Sinha, V., Thieser, J., Pouvesle, N., Taraborrelli, D., Tang, M. J., Bozem, H., Hosaynali-Beygi, Z., Axinte, R., Oswald, R., Novelli, A., Kubistin, D., Hens, K., Javed, U., Trawny, K., Breitenberger, C., Hidalgo, P. J., Ebben, C. J., Geiger, F. M., Corrigan, A. L., Russell, L. M., Ouwersloot, H. G., Vilà-Guerau de Arellano, J., Ganzeveld, L., Vogel, A., Beck, M., Bayerle, A., Kampf, C. J., Bertelmann, M., Köllner, F., Hoffmann, T., Valverde, J., González, D., Riekkola, M.-L., Kulmala, M., and Lelieveld, J.: The summertime Boreal forest field measurement intensive (HUMPPA-COPEC-2010): an overview of meteorological and chemical influences, Atmos. Chem. Phys., 11, 10599-10618, doi:10.5194/acp-11-10599-2011, 2011.
Witte, J. C., Douglass, A. R., da Silva, A., Torres, O., Levy, R., and Duncan, B. N.: NASA A-Train and Terra observations of the 2010 Russian wildfires, Atmos. Chem. Phys., 11, 9287-9301, doi:10.5194/acp-11-9287-2011, 2011.

Yu, H., Liu, S., and Dickinson, R.: Radiative effects of aerosols on the evolution of the atmospheric boundary layer, J. Geophys. Res., 107, 4142, doi:10.1029/2001JD000754, 2002.

Yurganov, L. N., Rakitin, V., Dzhola, A., August, T., Fokeeva, E., George, M., Gorchakov, G., Grechko, E., Hannon, S., Karpov, A., Ott, L., Semutnikova, E., Shumsky, R., and Strow, L.: Satellite- and ground-based CO total column observations over 2010 Russian fires: accuracy of top-down estimates based on thermal IR satellite data, Atmos. Chem. Phys., 11, 7925-7942, doi:10.5194/acp-11-7925-2011, 2011. 